\title{
Synthesis and characterization of silica nanostructures for cotton leaf worm control
}

\author{
Haytham A. Ayoub ${ }^{1,2} \cdot$ Mohamed Khairy ${ }^{1}$ Farouk A. Rashwan ${ }^{1} \cdot$ \\ Hanan F. Abdel-Hafez ${ }^{2}$
}

Received: 22 February 2017/ Accepted: 19 May 2017/Published online: 27 May 2017

(C) The Author(s) 2017. This article is an open access publication

\begin{abstract}
Herein, silica nanostructures with various physicochemical characteristics were synthesized via surfactant-assisted methods. Potent entomotoxic effects of silica nanostructures were explored against cotton leaf worm (Spodoptera littoralis) for the first time by utilizing surface contact and feeding bioassay protocols. The mortality of the treated larvaes by surface contact was faster than feeding bioassay method. The results showed that the surface characteristics and particle size of silica nanostructures could effectively control their entomotoxic effects compared to commercial silica or even organic pesticides. It was also observed that the dead bodies of the insects became extremely dehydrated due to the damage of insect cuticular water barrier as a result of abrasion. Furthermore, the physical mode of action of silica nanostructures makes insects is unlikely to become physiologically resistant; hence, silica nanostructures can be efficiently used as a valuable tool in $S$. littoralis management programs.
\end{abstract}

Keywords Silica nanoparticles - Mesoporous materials · Nanocides $\cdot$ Plant protection $\cdot$ Spodoptera littoralis

\section{Introduction}

Nanomaterial research was prompted recently to develop novel nano-technological products, processes, and applications that promise special merits for saving human health

Mohamed Khairy

mohamed.khairy@science.sohag.edu.eg

1 Chemistry Department, Faculty of Science, Sohag University, Sohag 82524, Egypt

2 Plant Protection Research Institute, ARC, Dokki, Giza, Egypt and environment. The sustainable potentials of nanotechnology are oriented to save of raw materials, energy and water as well as reduce greenhouse gases and hazardous wastes to improve the future. As a result, the application of nanomaterials in the area of plant sciences (i.e., nutrients and/or pest control) has been extensively investigated to overcome the expected increases of global population without negative impacts to environment and/or public health [1-3]. For example, $\mathrm{Ag}, \mathrm{CuO}, \mathrm{MgO}$, and $\mathrm{ZnO}$ nanoparticles were presented as effective antimicrobial agents [4-8]. Amorphous silica nanoparticle $\left(\mathrm{SiO}_{2} \mathrm{NPs}\right)$ showed biological entomotoxic effects, although it is inert in nature and considered as a biocompatible material according to US Food and Drug Administration [9]. To the best of our knowledge, few papers have been reported to utilize such inorganic NPs alone and/or combined with organic ingredient for plant protection. Therefore, it is meaningful to investigate the pesticidal behaviors of the inorganic NPs or their formulations to reduce harmful organic pesticide usage, enhance durability and efficiency as well as overcome the physiological resistance of the pests [10-13].

Mesoporous metal oxides in nanometer scale have received much attention in the field of research because of their unique physical and chemical properties in terms of large surface areas, hydrothermal stability in organic and inorganic solution phases, and reduced densities [14, 15]. Therefore, several of mesoporous metal oxide nanoparticles have been recently synthesized with controlled compositions, structures, and morphologies due to their composition-, structure-, and morphology-dependent properties and applications [16-18]. Among various metal oxides, mesoporous silica nanostructures were extensively studied for their scientific and technological interests including separations, catalysis, sensing, and drug delivery 
[19-22]. Different mesoporous nanostructures, monoliths, fibers, spheres, tubes, thin films, and ellipse, were synthesized by utilizing organic/inorganic synthetic chemistry [20-25]. However, considerable efforts have been devoted to control the intrinsic features and enable specific functionality which is selected to align with targeted applications. Despite this significant progress, most of the synthesis procedures are too delicate which render them less viable for large-scale industrial applications.

Spodoptera littoralis is considered as one of the most serious and destructive pest not only for cotton plant, but also for other vegetable, ornamental, and field crops in Egypt. Previously, we have investigated the effect of commercial $\mathrm{SiO}_{2}$ on the second larval instar of $S$. littoralis. However, the key factors that control $\mathrm{SiO}_{2}$ nanostructure entomotoxic efficiency were not recognized yet $[12,13]$. In the present study, $\mathrm{SiO}_{2}$ nanostructures with various shapes and sizes have been synthesized by utilizing surfactantassisted methods [26]. Triton X100 (TX-100), cetyltrimethylammonium bromide (CTAB), and Polyvinylpyrrolidone (PVP) have been used as soft template. The entomotoxic effects of $\mathrm{SiO}_{2}$ nanostructures against $S$. littoralis are investigated by applying surface contact and feeding bioassay methods. Importantly, the synthesis conditions of $\mathrm{SiO}_{2}$ nanostructures are played significant role not only for control their physical properties, but also revealed variable entomotoxic effects against S. littoralis. The synthesized $\mathrm{SiO}_{2}$ nanostructures showed promising inorganic-based pesticide in S. littoralis management programs compared to commercial $\mathrm{SiO}_{2}$ materials.

\section{Experimental section}

\section{Chemicals}

All chemicals were used as received without further purification. Tetra methylorthosilicate (TMOS; 98\%), ethanol; 96\%, ammonium hydroxide $\left(\mathrm{NH}_{4} \mathrm{OH} ; 28 \%\right)$, triton X100 (TX-100), cetyltrimethylammonium bromide (CTAB), and polyvinylpyrrolidone (PVP) were obtained from Sigma-Aldrich Company LTD. Silica precipitated $\left(\mathrm{SiO}_{2}\right)$ was purchased from Fisher chemicals company, UK. All solutions were prepared using bidistilled water with resistivity more than $18.2 \mathrm{M} \Omega \mathrm{cm}$.

\section{Insects}

Laboratory strain of cotton leaf worm (S. littoralis) was cultured on leaves of the castor oil plant (Ricinus communis $L$ ) under constant laboratory conditions of $25 \pm 2{ }^{\circ} \mathrm{C}$ and $65 \pm 5 \%$ relative humidity $(\mathrm{RH})$ in Plant Protection
Research Institute, ARC, Dokki, Giza, Egypt. The second instar larval stage of the insect was used in the entomotoxic effect evaluations.

\section{Synthesis of silica nanostructures}

$\mathrm{SiO}_{2}$ nanostructures were synthesized by utilizing modified Stöber method. Three different surfactants of TX-100, CTAB, and PVP have been used [26].

$\mathrm{SiO}_{2}-\mathrm{TX}$

A mixture solution $(50 \mathrm{~mL})$ of $\mathrm{TX}-100$, ethanol, $\mathrm{NH}_{4} \mathrm{OH}$, and $\mathrm{H}_{2} \mathrm{O}$ with the final ratio $(0.2: 4.6: 1: 4)$ was stirred for $30 \mathrm{~min}$ at $50{ }^{\circ} \mathrm{C}$. A $3.0 \mathrm{~mL}$ of TMOS was injected dropwise to the mixture with constant rate of $10 \mu \mathrm{L} \mathrm{min}{ }^{-1}$. The final solution was diluted with $100 \mathrm{~mL} \mathrm{H}_{2} \mathrm{O}$ and left under continuous stirring for $42 \mathrm{~h}$. The formed silica sample was filtrated, washed several times by mixture solution of $\mathrm{H}_{2} \mathrm{O}$ and ethanol, and left to dry at $60-80{ }^{\circ} \mathrm{C}$. Finally, the remaining surfactant was removed by thermal treatment at $550{ }^{\circ} \mathrm{C}$ for $6 \mathrm{~h}$.

$\mathrm{SiO}_{2}-\mathrm{CTAB}$

A $2 \mathrm{~g}$ of CTAB mixed with $5 \mathrm{~mL}$ of TMOS. The mixture was transferred quantitatively to $250 \mathrm{~mL}$ round bottom flask containing a mixture solution of $3.2 \mathrm{~mL} \mathrm{NH} \mathrm{NH}_{4} \mathrm{OH}$, $20 \mathrm{~mL} \mathrm{H}_{2} \mathrm{O}$, and $143 \mathrm{~mL}$ ethanol. The flask contents were heated to $100{ }^{\circ} \mathrm{C}$ and left under constant stirring for $24 \mathrm{~h}$. The formed silica sample was filtrated, washed several times with a mixture of water and ethanol, and then left to dry at $80{ }^{\circ} \mathrm{C}$ overnight.

$\mathrm{SiO}_{2}-\mathrm{PVP}$

A mixture solution $(50 \mathrm{~mL})$ of PVP, ethanol, $\mathrm{NH}_{4} \mathrm{OH}$, and $\mathrm{H}_{2} \mathrm{O}$ with the final molar ratio $(0.2: 4.6: 1: 4)$ was formed and stirred for $30 \mathrm{~min}$ at $50{ }^{\circ} \mathrm{C}$. The mixture solution was diluted by $100 \mathrm{~mL} \mathrm{H}_{2} \mathrm{O}$. A $3.0 \mathrm{~mL}$ of TMOS was introduced with constant rate of $10 \mu \mathrm{L} \mathrm{min}{ }^{-1}$ and then left it under constant stirring for $42 \mathrm{~h}$. The formed silica sample was filtrated, washed several times with mixture of $\mathrm{H}_{2} \mathrm{O}$ and ethanol, and left to dry at $60-80{ }^{\circ} \mathrm{C}$. The remaining surfactant was removed by thermal treatment at $550{ }^{\circ} \mathrm{C}$ for $6 \mathrm{~h}$.

\section{Characterization of $\mathrm{SiO}_{2}$ nanostructures}

The morphology of the $\mathrm{SiO}_{2}$ samples was investigated using scanning electron microscopy (SEM, JEOL model $5400 \mathrm{LV}$ ). The $\mathrm{SiO}_{2}$ powders were ground and fixed onto a specimen stub using double-sided carbon tape. To obtain 
high-resolution micrographs, a $10 \mathrm{~nm}$ Pt film was coated on the $\mathrm{SiO}_{2}$ powder using anion sputtering (Hitachi E-1030) at room temperature. The SEM was operated at $20 \mathrm{keV}$ to obtain high-resolution SEM images. Transmission electron microscopy (TEM) of $\mathrm{SiO}_{2}$ samples was performed using a JEOL-JEM microscope model 2100. TEM was conducted at an acceleration voltage of $200 \mathrm{kV}$ to obtain a lattice resolution of $0.1 \mathrm{~nm}$. TEM images were recorded using a CCD camera. The $\mathrm{SiO}_{2}$ sample was dispersed in ethanol solution using an ultrasonic bath, and then dropped on a copper grid. Prior to inserting the samples into the TEM column, the grid was vacuum dried for $20 \mathrm{~min}$.

The textural surface properties and pore size distribution were determined by $\mathrm{N}_{2}$ adsorption/desorption isotherms at $73 \mathrm{~K}$ with a NOVA 3200 apparatus, USA. The specific surface area $\left(S_{\mathrm{BET}}\right)$ was calculated using the BrunauerEmmett-Teller (BET) method with multipoint adsorption data from the linear segment of the $\mathrm{N}_{2}$ adsorption isotherm. The pore size distribution was determined from the analysis of desorption branch of isotherm using Barrett-Joyner-Halenda $(\mathrm{BJH})$ method. FTIR spectra of silica samples were recorded between 4000 and $400 \mathrm{~cm}^{-1}$ on a Bruker ALPHA FT-IR spectrometer. A little amount of each sample was scratched off and ground with $\mathrm{KBr}$ to press pellets for recording their FTIR spectrum.

\section{Bioassays}

\section{Surface contact method}

The silica samples were uniformly distributed on the bottom surface of plastic containers at doses of $0.25,0.5$, and $1.0 \mathrm{mg} \mathrm{cm}^{-2}$. Silica-free container was used in the control set. The containers were covered with muslin cloth to allow aeration. Each treatment was repeated three times. About

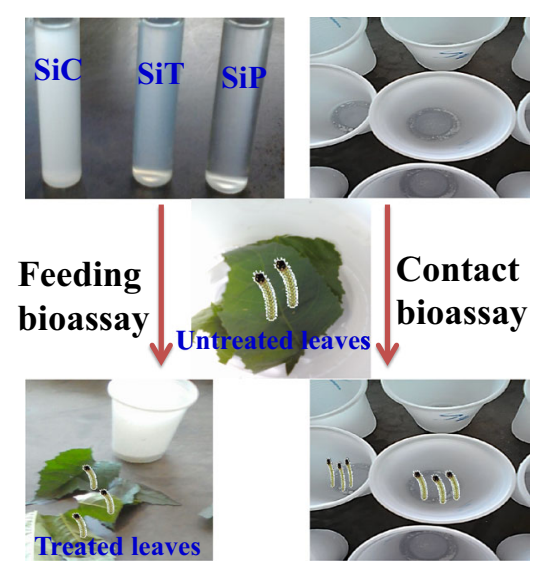

Scheme 1 Representation of feeding and contact method for cotton leaf worm control ten second instars larvae of $S$. littoralis were introduced to the container after distributing of the material (Scheme 1). All bioassays were performed at $25 \pm 2{ }^{\circ} \mathrm{C}$ and relative humidity (RH) of $65 \pm 5 \%$. Mortality of the insect was checked at particular days and the corrected percentages were statistically computed using Probit analysis program [27].

\section{Feeding method}

Feeding entomotoxic effect was performed via leaf dip bioassay method. Leaf discs of castor oil plant were prepared and dipped in a solution of 250, 500, and $1000 \mathrm{ppm}$ of silica samples. The untreated leaf discs of castor oil plant were used in control set. The containers were covered with muslin cloth to allow aeration. Each treatment was repeated three times. About ten second instars larvae of $S$. littoralis were introduced in each container (Scheme 1). All bioassays were performed at $25 \pm 2{ }^{\circ} \mathrm{C}$ and $\mathrm{RH}$ of $65 \pm 5 \%$. Insect mortality was checked at particular days. Their corrected percentages were statistically computed using Probit analysis program [27].

\section{Biochemical analysis}

The castor oil leaves were treated with $\mathrm{LC50}$ of $\mathrm{SiO}_{2}$-TX, $\mathrm{SiO}_{2}-\mathrm{CTAB}$, and $\mathrm{SiO}_{2}$-PVP nanostructures via feeding bioassay method for 3 days. Then, the survived $S$. littoralis were collected and allowed to grow on untreated/normal leaves until to reach the sixth instar larvae. The insects were homogenized for biochemical analysis in a chilled glass Teflon tissue homogenizer (ST-2 Mechanic-Preczyina, Poland). The supernatant was kept in a deep freezer at $-20{ }^{\circ} \mathrm{C}$ for further biochemical analysis. Total carbohydrates, total proteins, total lipids, lactate dehydrogenase (LED), phenol oxidase activity, and chitinase activity were estimated. The absorbance measurement of colored substances or metabolic compounds was performed using double beam UV/Vis spectrophotometer (Spectronic 1201, Milton Roy Co., USA).

\section{Results and discussion}

\section{Physicochemical Characteristics of $\mathrm{SiO}_{2}$ samples}

Surfactant-assisted method was employed to control the morphology of silica nanostructures. Three different synthesis compositions have been used to form micro-emulsion phases. Figure 1 shows SEM and TEM micrographs of synthesized $\mathrm{SiO}_{2}$ nanostructures in the presence of different structure directing agents: TX-100, CTAB, and PVP. In the presence of TX-100, the SEM image reveals the 

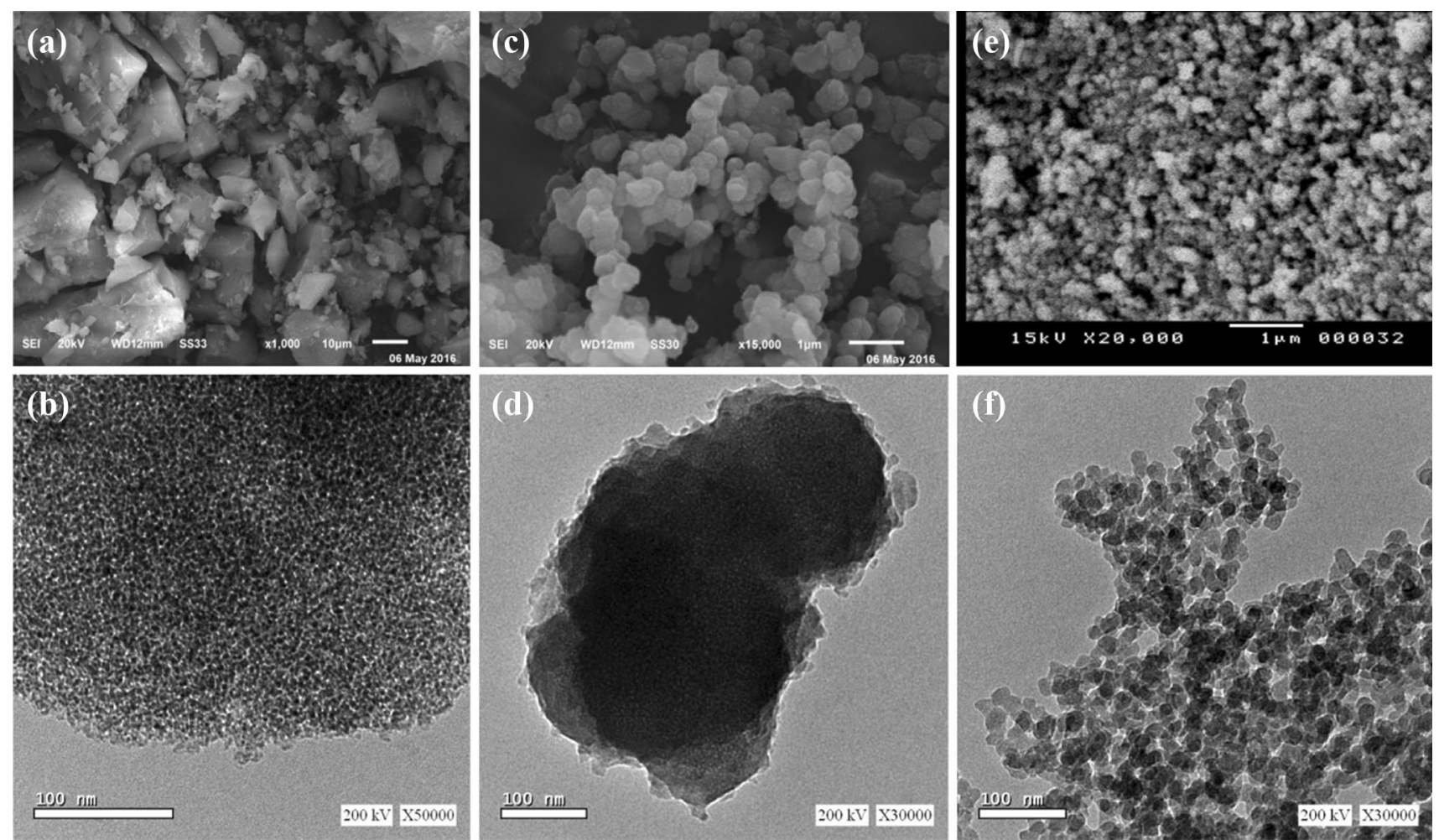

Fig. 1 SEM and TEM images of $\mathrm{SiO}_{2}-\mathrm{TX}(\mathbf{a}, \mathbf{b}), \mathrm{SiO}_{2}-\mathrm{CTAB}(\mathbf{c}, \mathbf{d})$, and $\mathrm{SiO}_{2}-\mathrm{PVP}(\mathbf{e}, \mathbf{f})$ samples prepared using surfactant-assisted method

formation of monolithic particles with plate-like morphology and average particle size about 5-10 $\mu \mathrm{m}$ (Fig. 1a). Aggregated spherical nanoparticles are formed in the presence of CTAB and PVP (Fig. 1c, e). Furthermore, the TEM micrographs exhibit surfactant-dependent size and morphology of $\mathrm{SiO}_{2}$ nanostructures. Figure $1 \mathrm{~b}$ shows monolith silica particles with a worm-like mesoporous network over a large area of monolithic structure. $\mathrm{SiO}_{2}$ CTAB sample shows aggregated sphere-like particles with an average diameter of $175 \mathrm{~nm}$. However, PVP surfactant reveals uniform and dispersed $\mathrm{SiO}_{2}$ nanostructures with sphere-like morphology; the average diameter is about $33 \mathrm{~nm}$. Such different sizes and shapes of silica nanostructures might offer several interesting physicochemical characteristics that provide more information for designing new inorganic pesticide formulations as well as leading to find out the key factors which control the interactions of $\mathrm{SiO}_{2}$ nanostructures with insect body.

$\mathrm{N}_{2}$ adsorption/desorption isotherms of silica nanostructures showed different surface areas and pore size distribution curves (Fig. 2 a). According to IUPAC classification; $\mathrm{SiO}_{2}$-TX presents type IV isotherm and $\mathrm{H} 2$ type hysteresis loop with the highest surface area $\left(S_{\mathrm{BET}}\right)$ of $634.5 \mathrm{~m}^{2} \mathrm{~g}^{-1}$. A well-defined steepness of adsorption/ desorption branch features cage-like mesopore with uniform cavities. However, $\mathrm{SiO}_{2}-\mathrm{CTAB}$ and $\mathrm{SiO}_{2}-\mathrm{PVP}$ revealed type IV isotherm with pronounced $\mathrm{H} 3$ hysteresis loop which could characterize slit-like mesopore entrance. The desorption branch of silica isotherms showed a stepwise behavior ended at the limiting pressure of the hysteresis closure, implying non-uniformity of the mesopore openings associated with pore constrictions and/or inkbottle pores with narrow necks. The specific surface areas of $\mathrm{SiO}_{2}$-CTAB and $\mathrm{SiO}_{2}$-PVP are $S_{\mathrm{BET}}=66$ and $158 \mathrm{~m}^{2} \mathrm{~g}^{-1}$, respectively. The lower surface area of $\mathrm{SiO}_{2}-$ $\mathrm{CTAB}$ is attributed to the presence of CTAB surfactant in mesoporous architectures network. Hence, the $\mathrm{SiO}_{2}-\mathrm{CTAB}$ sample did not treat thermally like $\mathrm{SiO}_{2}-\mathrm{TX}$ and $\mathrm{SiO}_{2}-\mathrm{PVP}$ to remove CTAB template. The existence of $\mathrm{CTAB}$ increases the hydrophilicity of $\mathrm{SiO}_{2}$ surface and thus changes the interfacial region between the solid $\mathrm{SiO}_{2}$ particle and the insect body wall. The $\mathrm{SiO}_{2}$ nanostructures exhibit uniform pore size distribution of 28.1, 8.5, and $9.76 \mathrm{~nm}$ for $\mathrm{SiO}_{2}-\mathrm{TX}, \mathrm{SiO}_{2}-\mathrm{CTAB}$, and $\mathrm{SiO}_{2}-\mathrm{PVP}$, respectively. The mesoporous network of $\mathrm{SiO}_{2}$ nanostructures might be more suitable for the adsorption of small and large biomolecules in case of $\mathrm{SiO}_{2}$ contact with the insect body wall $[22,23]$. These features are very useful to describe the entomotoxic effects based on surface area and/ or lipid- or protein-dependent mechanism.

The chemical state of the $\mathrm{SiO}_{2}$ nanostructures and commercial $\mathrm{SiO}_{2}$ was confirmed using Fourier transform infrared spectroscopy FTIR. The FTIR spectra of $\mathrm{SiO}_{2}$ samples in the region $4000-400 \mathrm{~cm}^{-1}$ are explored 
Fig. 2 a Nitrogen adsorption/ desorption isotherm and their corresponding pore size distribution curves for $\mathrm{SiO}_{2}$-TX, $\mathrm{SiO}_{2}-\mathrm{PVP}$, and $\mathrm{SiO}_{2}-\mathrm{CTAB}$. b FTIR spectra of commercial $\mathrm{SiO}_{2}, \mathrm{SiO}_{2}-\mathrm{TX}, \mathrm{SiO}_{2}-\mathrm{PVP}$, and $\mathrm{SiO}_{2}-\mathrm{CTAB}$

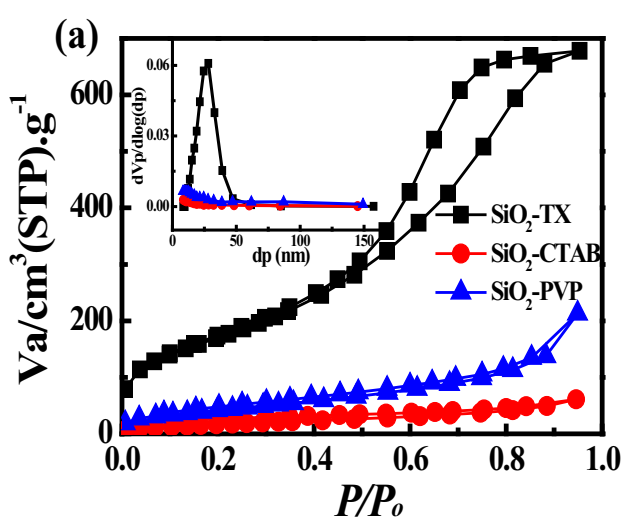

(Fig. 2b). The FTIR spectra of synthesized $\mathrm{SiO}_{2}$ nanostructures are almost the same as commercial $\mathrm{SiO}_{2}$. The strong and weak bands are centered at 1079, 799, and $459 \mathrm{~cm}^{-1}$; these bands are attributed to the $\mathrm{Si}-\mathrm{O}-\mathrm{Si}$ bond corresponding to bending and stretching vibrations, respectively [28]. The absorption bands at $2856 \mathrm{~cm}^{-1}$ and at $2927 \mathrm{~cm}^{-1}$ for $\mathrm{SiO}_{2}-\mathrm{CTAB}$ sample are assigned to $-\mathrm{CH}_{2}$ group of CTAB. Furthermore, the absorption band at $959 \mathrm{~cm}^{-1}$ of $\mathrm{SiO}_{2}-\mathrm{CTAB}$ is attributed to the hydroxyl group $(\mathrm{Si}-\mathrm{OH})$; this band disappears after thermal treatment at $550{ }^{\circ} \mathrm{C}$ for $6 \mathrm{~h}$ [29]. These results suggested the existence of hydroxyl groups on the $\mathrm{SiO}_{2}$ surfaces.

\section{Cotton leaf worm control}

Insecticide bioassay is often used to estimate the median lethal dose (LD50) or median lethal concentration (LC50) with associated $95 \%$ confidence intervals from a dose-response model. The LD50 or LC50 is the amount of insecticide required to kill $50 \%$ of a given population or strain under the specified conditions. Several standard methods such as topical application, residual or surface contact, immersion, and feeding bioassays have been commonly employed to determine the relationship between pesticides administered amount (i.e., dose or concentration) and its response magnitude for living organisms [30]. In this study, we have focused on surface contact and feeding bioassay methods to evaluate the entomotoxic effect of $\mathrm{SiO}_{2}$ nanostructures against $S$. littoralis.

\section{Surface contact bioassay}

The contact entomotoxic effect of the synthesized $\mathrm{SiO}_{2}$ nanostructures has been explored and compared to commercial silica materials (Scheme 1). The $\mathrm{SiO}_{2}$ powders that were uniformly distributed on the bottom of plastic vessels contain different doses of $0.25,0.5$, and $1.0 \mathrm{mg} \mathrm{cm}^{-2}$ at $25 \pm 2{ }^{\circ} \mathrm{C}$. The $S$. littoralis mortality was checked at certain days, as shown in Fig. 3. Interestingly, the commercial

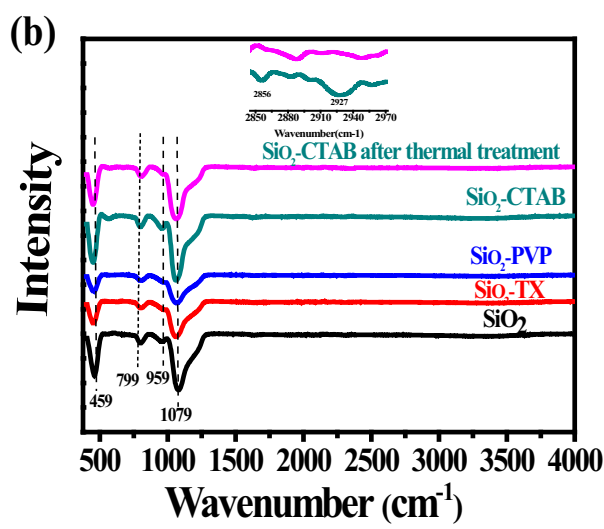

$\mathrm{SiO}_{2}$ material has no entomotoxic effects during the first 3 days and the corresponding contact mortality was evaluated to be zero. After that, the mortality was increased up to $100 \%$ in the 11th day of treatment (Fig. 3a). However, the synthesized $\mathrm{SiO}_{2}$ nanostructures showed an efficient $S$. littoralis control with high mortality from the first exposure days. In the first day, the mortality percentage was estimated to be 29.6, 29.1, and $28.1 \%$ for $\mathrm{SiO}_{2}-\mathrm{TX}, \mathrm{SiO}_{2}-$ $\mathrm{CTAB}$, and $\mathrm{SiO}_{2}-\mathrm{PVP}$, respectively. The mortality was increased up to $96.6,93.3$, and $90.0 \%$ in the third day of exposure. The median lethal doses (LD50) were calculated to be $0.61,0.58$, and $0.57 \mathrm{mg} \mathrm{cm}^{-2}$ after 3 days compared to $0.495 \mathrm{mg} \mathrm{cm}^{-2}$ for commercial $\mathrm{SiO}_{2}$ after 7 days (Fig. 3). There are several mechanisms for inorganic materials toxicity which have been recently reported including generation of reactive oxygen species, oxidative stress, membrane disruption, protein unfolding, and/or inflammation. The results showed that the surface area of $\mathrm{SiO}_{2}$ nanostructures has no significant key role in the absorption of lipids present in insect cuticle. Therefore, the dehydration of the insect body caused by $\mathrm{SiO}_{2}$ dust was mainly due to acute damage of the cuticular water barrier as a result of abrasion, and the insects began to lose the water from their bodies and died due to desiccation [31, 32]. Significantly, the surface contact bioassay is independent of particle size and morphology but mainly controlled by the hydrophilicity of the $\mathrm{SiO}_{2}$ surfaces. The presence of small amount of surfactant in $\mathrm{SiO}_{2}-\mathrm{CTAB}$ does not have any effect on the mortality values, indicating that the hydrophilic surfaces of synthesized $\mathrm{SiO}_{2}$ nanostructures might only enhance the entomotoxic rate (Fig. 3c).

\section{Feeding bioassay}

Feeding experiment was performed by dipping of castor oil leaf in $\mathrm{SiO}_{2}$ suspension (Scheme 1). Three suspension solutions containing 250, 500, and $1000 \mathrm{ppm}$ of $\mathrm{SiO}_{2}$ nanostructures were prepared in the presence of $0.1 \%(\mathrm{~V} /$ V) Triton $\mathrm{X}-100$ at $25{ }^{\circ} \mathrm{C}$ as recommend in pesticide 
Fig. 3 Accumulative mortality at indicated days of $S$. littoralis exposed to different doses of commercial $\mathrm{SiO}_{2}, \mathrm{SiO}_{2}-\mathrm{TX}$, $\mathrm{SiO}_{2}-\mathrm{PVP}$, and $\mathrm{SiO}_{2}-\mathrm{CTAB}$ via surface contact bioassay
Fig. 4 Accumulative mortality after 11 days of the post treatments (a), pupation (b), pupa malformation (c), and adult emergence (d) of $S$. littoralis exposed to dried and treated leaf discs of castor oil plant with different concentrations of commercial $\mathrm{SiO}_{2}, \mathrm{SiO}_{2}-\mathrm{TX}, \mathrm{SiO}_{2}-\mathrm{PVP}$, and $\mathrm{SiO}_{2}-\mathrm{CTAB}$ via feeding bioassay
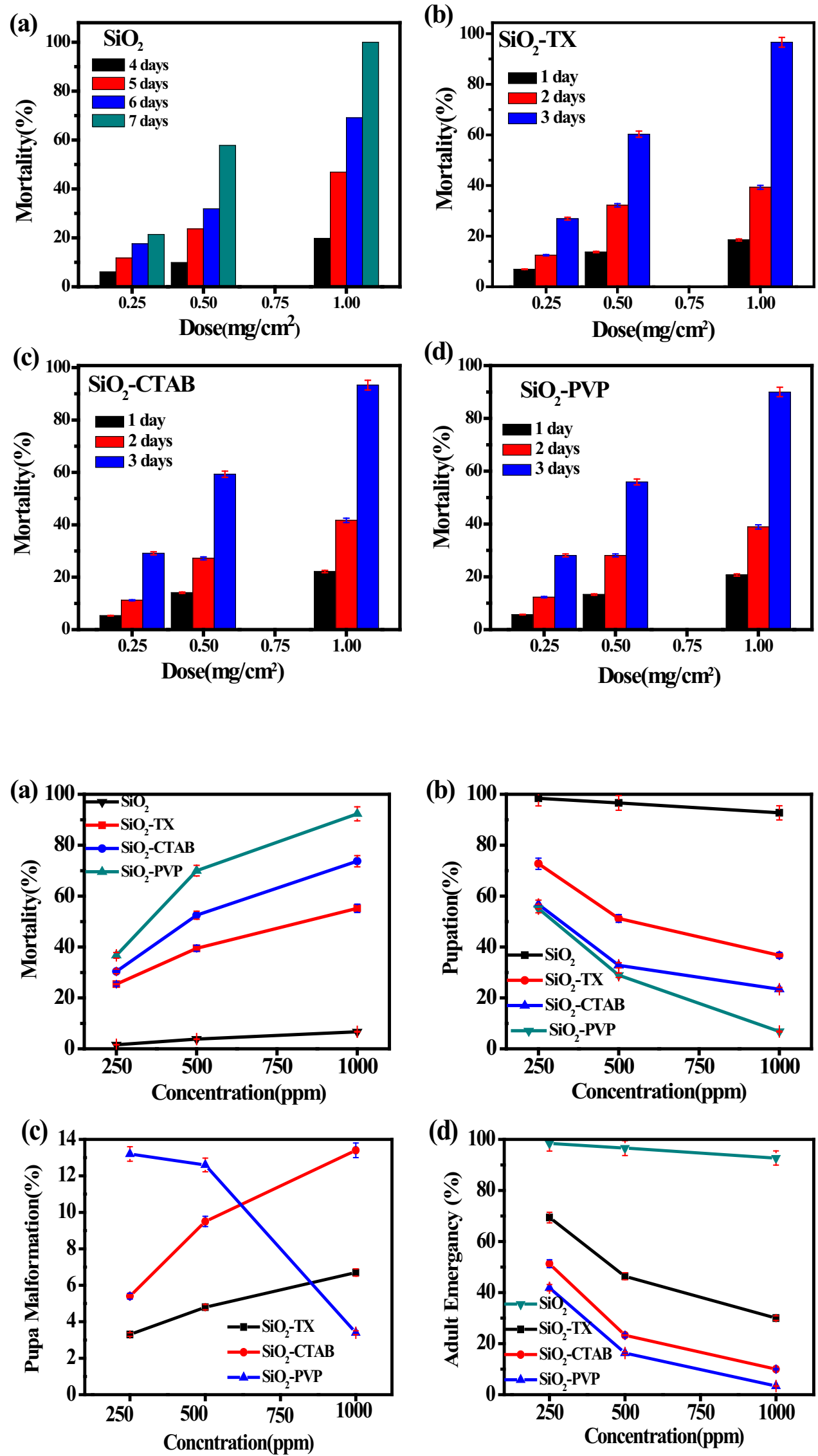
formulations [33]. Figure 4a shows feeding entomotoxic effect for commercial and synthesized $\mathrm{SiO}_{2}$ nanostructures. After 11 days of the treatment, accumulative mortality and post emergence for commercial silica were closely to that of control set experiment even at higher concentrations, i.e., $1000 \mathrm{ppm}$. However, the synthesized $\mathrm{SiO}_{2}$ nanostructures showed variable intensive entomotoxic effects. The accumulative mortalities using $1000 \mathrm{ppm}$ were about 52.3, 73.1, and $92.2 \%$ for $\mathrm{SiO}_{2}-\mathrm{TX}, \mathrm{SiO}_{2}-\mathrm{CTAB}$, and $\mathrm{SiO}_{2}-\mathrm{PVP}$, respectively. The accumulative mortality of $\mathrm{SiO}_{2}-\mathrm{PVP}$ was almost double of $\mathrm{SiO}_{2}$-TX. This result revealed that the entomotoxic effect of the synthesized $\mathrm{SiO}_{2} \mathrm{NPs}$ is mainly dominated by particle size compared to surface characteristic effect as in the previous contact experiment. The corresponding LC50 values were calculated after 11 days to be 795, 464.2, and 327.7 ppm for $\mathrm{SiO}_{2}-\mathrm{TX}, \mathrm{SiO}_{2}-\mathrm{CTAB}$, and $\mathrm{SiO}_{2}$-PVP, respectively (Fig. 4a). The LC50 of methomyl against $S$. littoralis is about $434.49 \mathrm{ppm}$ after 1 day of exposure under the same experimental conditions. Methomyl is a broad-spectrum carbamate insecticide. It has been used in a wide range of agriculture products, although it was considered as highly toxic organic pesticide for birds and mammals [34]. Although $\mathrm{SiO}_{2}$-TX has the highest surface area, it showed the lowest entomotoxic effect with LC50 $=795 \mathrm{ppm}$. This observation indicated that surface area is not important factor, especially there is no strong effect for the absorption of lipids present in insect cuticle. Intensive morphological changes of the dead sixth instar of treated larvae have been observed compared with that in control set (Fig. 5a). The biological aspects including pupation, pupa malformation, and adult emergency were investigated (Fig. 4b-d). It was found that the survived treated larvaes with commercial silica transferred to adult insects without any pupa malformation closely to the control set (Fig. 5b). This result indicated that the feeding of commercial silica has no entomotoxic effect against $S$.

(a)

(b)
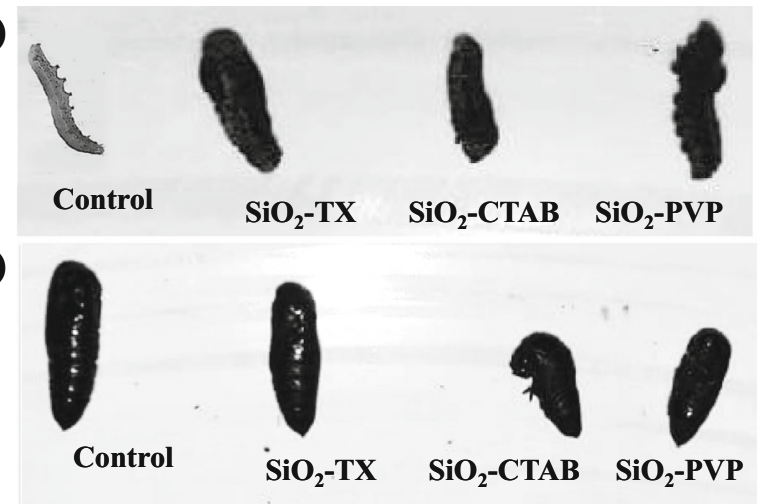

Fig. 5 Photographic images of a sixth instars and $\mathbf{b}$ pupa malformation for $S$. littoralis exposed to $1000 \mathrm{ppm}$ of $\mathrm{SiO}_{2}-\mathrm{TX}, \mathrm{SiO}_{2}-\mathrm{PVP}$, and $\mathrm{SiO}_{2}-\mathrm{CTAB}$ by feeding bioassay littoralis in contrast with synthesized silica nanostructures. The pupa malformations were estimated to be 6.7, 13.4, and $3.4 \%$ for treated larvaes with $\mathrm{SiO}_{2}-\mathrm{TX}, \mathrm{SiO}_{2}-\mathrm{CTAB}$, and $\mathrm{SiO}_{2}-\mathrm{PVP}$, respectively. Such malformations in pupa stage affect on the final percentage of the adult emergence. Hence, the entire malformed pupas do not succeed to transform into adult insects. These results suggested that silica nanostructures are more effective on adults than larvaes. Therefore, the mortality is attributed to the impairment of the digestive tract and surface enlargement of the integument as a consequence of dehydration or blockage of spiracles and tracheas. Such intensive damage sorption and abrasion might be due to the generation of reactive oxygen radicals in aqueous suspensions of the synthesized silica nanoparticles. Both homolytic ( $\mathrm{Si} \cdot \mathrm{SiO} \cdot)$ and heterolytic $\left(\mathrm{Si}^{+}, \mathrm{SiO}^{-}\right)$cleavages might take place in the silicon-oxygen bond through particle cracking in digestion tract. These radicals stabilized as a surface bound reactive oxygen species and then decay subsequently [35]. Therefore, biochemical analyses have been performed to investigate the exposed particle surfaces which could interact with the insect.

\section{Biochemical impacts}

The biochemical changes in living organisms that exposed to insecticides provide some clues of their mode of actions. Total carbohydrate content of the sixth instars of $S$. littoralis treated with $\mathrm{LC} 50$ of $\mathrm{SiO}_{2}$ nanostructures was estimated (Fig. 6a). A significant decrease can be observed: $-52.7,-32.43$, and $-27.71 \%$ for $\mathrm{SiO}_{2}$-TX, $\mathrm{SiO}_{2}-\mathrm{CTAB}$, and $\mathrm{SiO}_{2}-\mathrm{PVP}$, respectively. The reduction in total soluble carbohydrate content of the treated larvaes could be attributed to metamorphic changes in larvaes. Hence, the carbohydrate content supplies the body with glucose and provides an energy source for synthesis of larvae and adult tissues, especially the cuticle [36, 37]. Therefore, the deficiency in carbohydrates content has been leading to pupa malformation (Fig. 5b). Furthermore, a marked diminution in total proteins content of the sixth instars of $S$. littoralis: $-47.6,-44.11$, and $-23.36 \%$ treated with $\mathrm{SiO}_{2}$-TX, $\mathrm{SiO}_{2}-\mathrm{CTAB}$, and $\mathrm{SiO}_{2}-\mathrm{PVP}$, respectively (Fig. 6b). Such reduction of total protein content might be attributed to protein leakage during intoxication that caused a significant lack in body weight, conversion of protein to amino acids, and degradation of protein to release energy or the direct effect of the tested materials on the amino acids transport of the cell [38].

The change in the total lipid content of the sixth instars of $S$. littoralis treated with LC50 of silica nanostructures was presented in Fig. 6c. The total lipid content was slightly decreased: $-28.95,-5.26$, and $-2.63 \%$ for $\mathrm{SiO}_{2}-$ 

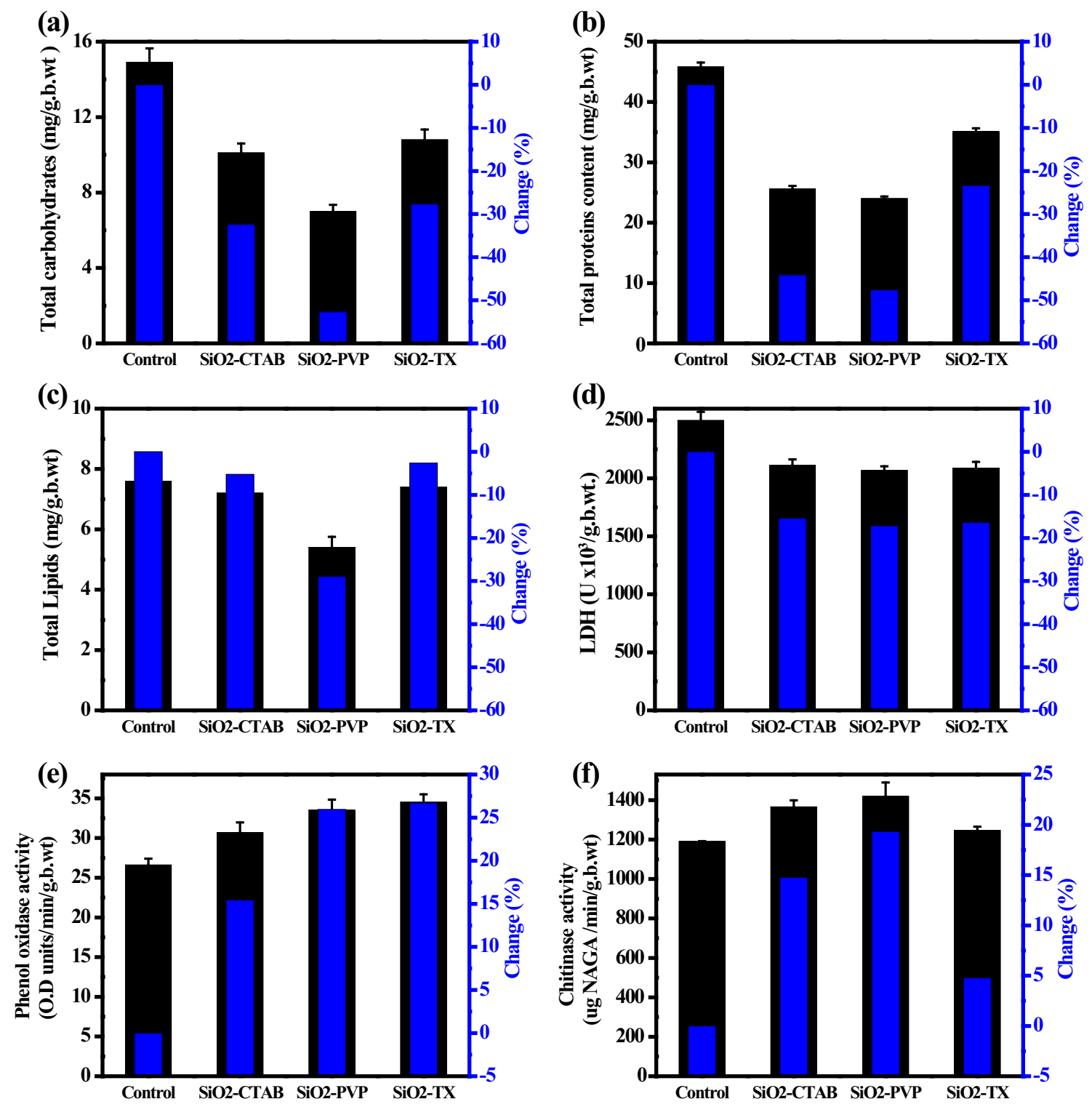

Fig. 6 Total carbohydrates (a), total protein content (b), total lipids (c), LDH (d), phenol oxidase activity (e), and chitinase activity (f) of the sixth instars of $S$. littoralis treated with $\mathrm{LC} 50$ of $\mathrm{iO}_{2}-\mathrm{TX}, \mathrm{SiO}_{2}-\mathrm{PVP}$, and $\mathrm{SiO}_{2}-\mathrm{CTAB}$ via feeding bioassay

$\mathrm{TX}, \mathrm{SiO}_{2}-\mathrm{CTAB}$, and $\mathrm{SiO}_{2}-\mathrm{PVP}$, respectively. This result clearly confirmed our suggestion; there is no strong effect for the absorption of lipids present in insect cuticle. Although $\mathrm{SiO}_{2}$-TX sample has the highest surface area, it has the lowest effect on total lipids content (Fig. 2a). Therefore, the dehydration of the insect body caused by surface reactive silica particles was mainly due to the acute damage of the cuticular water barrier as a result of abrasion [39]. Furthermore, lactate dehydrogenase (LDH) activity of S. littoralis in the sixth instars was also decreased: -17.18 , -15.41 , and $-16.42 \%$ for $\mathrm{SiO}_{2}-\mathrm{TX}, \mathrm{SiO}_{2}-\mathrm{CTAB}$, and $\mathrm{SiO}_{2}$-PVP, respectively (Fig. 6d). This observation supports a physical mode of action of $\mathrm{SiO}_{2}$ nanostructures with a weak chemical stress upon $S$. littoralis in contrast with the traditional organic pesticides which caused a strong chemical stress [40].

Phenol oxidase (PO) is an important component of $S$. littoralis immune systems. Figure 6e illustrates the phenol oxidase activity of $S$. littoralis treated with silica nanostructures. It was found that the PO activity was increased in the following: $+25.94,+15.42$, and $+26.7 \%$ for $\mathrm{SiO}_{2}-\mathrm{TX}, \mathrm{SiO}_{2}-\mathrm{CTAB}$, and $\mathrm{SiO}_{2}-\mathrm{PVP}$, respectively. In general, PO activity is correlated with the resistance of the insect to pathogens [41]. The lower activity of phenol oxidase using $\mathrm{SiO}_{2}$-CTAB is attributed to the presence of surfactant-coated silica particles. Furthermore, the chitinase activity was also increased (Fig. 6f): $+19.32,+14.78$, and $+4.79 \%$ for $\mathrm{SiO}_{2}$-TX, 
$\mathrm{SiO}_{2}-\mathrm{CTAB}$, and $\mathrm{SiO}_{2}-\mathrm{PVP}$, respectively. The hyperchitinase activity might be attributed to chitin synthesis inhibitor or may be a secondary effect for the reduced activity of $\beta$-ecdysone metabolizing enzymes followed by $\beta$-ecdysone accumulation [42, 43]. In general, the mentioned biochemical analyses provide a clear evidence for the hypothesis of physical mode action of $\mathrm{SiO}_{2}$ NPs due to the impairment of the digestive tract and generation of reactive $\mathrm{SiO}_{2}$ surfaces in the aqueous formulations. So far, the application of silica NPs in inorganic pesticide program will offer many advantages over the traditional organic pesticide control as:

1. The insects are unlikely to become genetically selected or physiologically resistance $[42,43]$.

2. The inorganic formulations based on nanomaterials will reduce the environment risk. Over than 2.8 million tons of organic pesticides are used annually over the world. It has been estimated that only $0.1 \%$ of applied pesticides reach the target pests, leaving the bulk of the pesticides in water supplier and soil.

3. Saving the water resources particularly in case of no testing for toxic residue levels in developing countries. Energy and raw materials that might be used for cleaning and decontamination of the water will be utilized.

4. Development of sustainable strategy for cotton leaf worm control that enhances the productivity of such essential crops in Mediterranean area.

\section{Conclusion}

$\mathrm{SiO}_{2}$ nanostructures have been synthesized via surfactantassisted method and utilized for cotton leaf worm control. The entomotoxic effects of $\mathrm{SiO}_{2} \mathrm{NPs}$ were explored by surface contact and feeding bioassay methods. Interestingly, the commercial silica did not show any entomotoxic effect on treated larvaes by feeding bioassay and slower entomotoxic effect in surface contact experiment. However, the synthesized silica nanostructures exhibited intensive entomotoxic effect in both bioassay methods. It was observed that the dead bodies of the insects became extremely dehydrated due to the damage of insect cuticular water barrier as a result of abrasion. This hypothesis for the physical mode of action makes the use of nanopesticide stronger and insects are unlikely to become genetically selected or having no physiological resistant to such a type of materials. The usage of inorganic nanopesticides might open a new avenue for plant protection that definitely enhances environmental and economic benefits compared to toxic and persistent organic pesticides.
Open Access This article is distributed under the terms of the Creative Commons Attribution 4.0 International License (http://crea tivecommons.org/licenses/by/4.0/), which permits unrestricted use, distribution, and reproduction in any medium, provided you give appropriate credit to the original author(s) and the source, provide a link to the Creative Commons license, and indicate if changes were made.

\section{References}

1. Wang, X., Liu, Y., Zhang, H., Shen, X., Cai, F., Zhang, M., Gao, Q., Chen, W., Wang, B., Tao, S.: The impact of carbon nanotubes on bioaccumulation and translocation of phenanthrene, $3-\mathrm{CH}_{3}-$ phenanthrene and 9- $\mathrm{NO}_{2}$-phenanthrene in maize (Zea mays) seedlings. Environ. Sci. Nano. 3, 818-829 (2016)

2. Gogos, A., Knauer, K., Bucheli, T.: Nanomaterials in plant protection and fertilization: current state, foreseen applications, and research priorities. J. Agric. Food Chem. 60, 9781-9792 (2012)

3. Raliya, R., Franke, C., Chavalmane, S., Nair, R., Reed, N., Biswas, P.: Quantitative understanding of nanoparticle uptake in watermelon plants. Front. Plant Sci. 7, 1288 (2016)

4. Reed, R.B., Zaikova, T., Barber, A., Simonich, M., Lankone, R., Marco, M., Hristovski, K., Herckes, P., Passantino, L., Fairbrother, D.H., Tanguay, R., Ranville, J.F., Hutchison, J.E., Westerhoff, P.K.: Potential environmental impacts and antimicrobial efficacy of silver- and nanosilver- containing textiles. Environ. Sci. Technol. 7, 4018-4026 (2016)

5. Byeon, J.H.: Rapid green assembly of antimicrobial nanobunches. Sci. Rep. 6, 27006 (2016)

6. Purwajanti, S., Zhou, L., Nor, Y.A., Zhang, J., Zhang, H., Huang, $\mathrm{X}$., Yu, C.: Synthesis of magnesium oxide hierarchical microspheres: a dual-functional material for water remediation. ACS Appl. Mater. Inter. 38, 21278-22128 (2015)

7. Khan, M.F., Ansari, A.H., Hameedullah, M., Ahmad, E., Husain, F.M., Zia, Q., Baig, U., Zaheer, M.R., Alam, M.M., Khan, A.M., Al Othman, Z.A., Ahmad, I., Aliev, G.M.A.G.: Sol-gel synthesis of thorn-like $\mathrm{ZnO}$ nanoparticles endorsing mechanical stirring effect and their antimicrobial activities: potential role as nanoantibiotics. Sci. Rep. 6, 27689 (2016)

8. Jingzhe, X., Zhihui, L., Ping, L., Yaping, D., Yi, C., Qingsheng, W.: A residue-free green synergistic antifungal nanotechnology for pesticide thiram by $\mathrm{ZnO}$ nanoparticles. Sci. Rep. 4, 5408 (2014)

9. US Food and Drug Administration's Website. GRN No. 321: Synthetic amorphoussilica, http://www.accessdata.fda.gov/ scripts/fcn/gras_notices/GRN000321.pdf. 21 May 2014

10. Gerstl, Z., Nasser, A., Mingelgrin, U.: Controlled release of pesticides into soils from clay-polymer formulations. J. Agric. Food Chem. 46, 3797-3809 (1998)

11. Xiang, Y., Wang, N., Song, J., Cai, D., Wu, Z.: Micro-nanopores fabricated by high-energy electron beam irradiation: suitable structure for controlling pesticide loss. J. Agric. Food Chem. 22, 5215-5219 (2013)

12. Osman, H.H., Abdel-Hafez, H.F., Khidr, A.A.: Comparison between the efficacy of two nano-particles and effective microorganisms on some biological and biochemical aspects of Spodoptera littoralis. IJAIR. 3, 1620-1626 (2015)

13. Spodoptera litura Fabricious: European and mediterranean plant protection organization (EPPO). EPPO Bull. 9, 142-146 (2008)

14. Walcarius, A., Sibottier, E., Etienne, M., Ghanbaja, J.: Electrochemically assisted self-assembly of mesoporous silica thin films. J. Nat. Mater. 6, 602-608 (2007)

15. El-Safty, S.A., Khairy, M., Shenashen, M.A., Elshehy, E., Warkocki, W., Sakai, M.: Optical mesoscopic membrane sensor 
layouts for water- free and blood-free toxicants. Nano Res. 8, 3150-3163 (2015)

16. Mahmoud, B.G., Khairy, M., Rashwan, F.A., Foster, C.W., Banks, C.E.: Self-assembly of porous copper oxide hierarchical nanostructures for selective determinations of glucose and ascorbic acid. RSC Adv. 6, 14474-14482 (2016)

17. Khairy, M., El-Safty, S.A.: Mesoporous NiO nanoarchitectures for electrochemical energy storage: influence of size, porosity, and morphology. RSC Adv. 3, 23801-23809 (2013)

18. Largeot, C., Portet, C., Chmiola, J., Taberna, P.-L., Gogotsi, Y., Simon, P.: Relation between the ion size and pore size for an electric double-layer capacitor. J. Am. Soc. 9, 2730-2731 (2008)

19. El-Safty, S.A., Shenashen, M.A., Ismael, M., Khairym, M.: Mesocylindrical Aluminosilica monolith biocaptors for size-selective macromolecule cargos. Adv. Funct. Mater. 22, 3013-3021 (2012)

20. Chen, Y., Chen, H., Ma, M., Chen, F., Guo, L., Zhang, L., Shi, J.: Double mesoporous silica shelled spherical/ellipsoidal nanostructures: synthesis and hydrophilic/hydrophobic anticancer drug delivery. J. Mater. Chem. 21, 5290-5298 (2011)

21. Khairy, M., El-Safty, S.A., Shenashen, M.A., Elshehy, E.A.: Hierarchical inorganic-organic multi-shell nanospheres for intervention and treatment of lead-contaminated blood. Nanoscale. 5, 7920-7927 (2013)

22. Niu, Z., Kabisatpathy, S., He, J., Lee, L.A., Rong, J., Yang, L., Sikha, G., Popov, B.N., Emrick, T.S., Russell, T.P., Wan, Q.: Synthesis and characterization of bionanoparticle -Silica composites and mesoporous silica with large pores. Nano Res. 2, 474-483 (2009)

23. El-Safty, S.A., Shenashen, M.A., Khairy, M.: Bioadsorption of proteins on large mesocage-shaped mesoporous alumina monoliths. Colloid Surf. B 103, 288-297 (2013)

24. Xu, P., Chen, C., Li, X.: Mesoporous-silica nanofluidic channels for quick enrichment/extraction of trace pesticide molecules. Sci. Rep. 5, 17171 (2015)

25. El-Safty, S.A., Shenashen, M.A., Khairy, M.: Optical detection/collection of toxic Cd (II) ions using cubic Ia3d aluminosilica mesocage sensors. Talanta 98, 69-78 (2012)

26. StÖber, W., Fink, A., Bohn, E.: Controlled growth of monodisperse silica spheres in the micron size range. J. Colloid Interface Sci. 26, 62-69 (1968)

27. Finney, D.J.: Probit analysis, 3rd edn, p. 333. Cambridge Univ. Press, London (1971)

28. Zhang, X., Xia, B., Ye, H., Zhang, Y., Xiao, B., Yan, L., Lv, H., Jiang, B.: One-step sol-gel preparation of PDMS-silica ORMOSILs as environment-resistant and crack-free thick antireflective coatings. J. Mater. Chem. 22, 13132-13140 (2012)

29. Zhang, M., Wu, Y., Feng, X., He, X., Chen, L., Zhang, Y.: Fabrication of mesoporous silica-coated CNTs and application in size-selective protein separation. J. Mater. Chem. 20, 5835-5842 (2010)
30. Zhu, K.Y.: Insecticide bioassay. Encyclopedia of entomology, pp. 1974-1976. Springer, Berlin (2008)

31. Debnath, N., Das, S., Seth, D., Chandra, R., Bhattacharya, SCh., Goswami, A.: Entomotoxic effect of silica nanoparticles against Sitophilus oryzae (L.). J. Pest. Sci. 84, 99-105 (2011)

32. Debnath, N., Mitra, S., Das, S., Goswami, A.: Synthesis of surface functionalized silica nanoparticles and their use as entomotoxic nanocides. Powder Technol. 221, 252-256 (2012)

33. Memarizadeh, N., Ghadamyari, M., Adeli, M., Talebi, K.: Linear-dendritic copolymers/indoxacarb supramolecular systems: biodegradable and efficient nano-pesticides. Environ. Sci. Process. Impacts 16, 2380-2389 (2014)

34. Abdien, S.A., Ahmed, M.A.I., AbduAllah, G.A.M., Ezz El-Din, H.A.: Potential evaluation of certain conventional pesticides on fourth instar larvae of cotton leaf worm, Spodoptera littoralis (Boisd.) (Lepidoptera: Noctuidae) under laboratory conditions. Adv. Environ. Biol. 10, 282-287 (2016)

35. Fubini, B., Hubbard, A.: Reactive oxygen species (ROS) and reactive nitrogen species (RNS) generation by silica in inflammation and fibrosis. Free Radical Biol. Med. 34, 1507-1516 (2003)

36. Chippenadale, G.M.: In: Rockstein, M. (ed.) The function of carbohydrates in insect life processes Biochemistry of insects, pp. 2-54. Academic press, New York (1978)

37. El-Sheikh, T.A.A., Rafea, H.S., El-Aasar, A.M., Ali, S.H.: Biological and biochemical effects of Bacillus thuringiensis, Serratia marcescens and Teflubenzuron on cotton leafworm, Egypt. J. Agric. Res. 91, 1327-1345 (2013)

38. Rawi, S.M., El-Gindy, H., Haggag, A.M., Aboul El-Hassan, A., Abdel-Kader, A.: New possible molluscicides from Calendula mircantha officinalis and Ammi majus plants. I. Physiological effect on B. alexandrina and B. trucatus. J. Egypt Ger. Soc. Zool. 16, 49-75 (1995)

39. Knight, J.A., Anderson, S., Rawle, J.M.: Chemical basis of the sulfo-phospho-vanillin reaction for estimating total serum lipids. Clin. Chem. 18, 199-202 (1972)

40. Abdel-Aziz, H.S.: Effect of some insecticides on certain enzymes of Spodoptera littoralis, Egypt. J. Agric. Res. 92, 501-512 (2014)

41. Nigam, Y., Maudlin, I., Welburn, S., Ratcliffe, N.A.: Detection of phenoloxidase activity in the hemolymph of tsetse flies, refractory and susceptible to infection with Trypanosoma brucei rhodesiense. J. Invertebr. Pathol. 69, 279-281 (1997)

42. Waterhouse, D.F., Hockman, R.H., Mckellar, J.W.: An investigation of chitinase activity in cockroach and termite extracts. J. Insect Physiol. 6, 96-112 (1961)

43. Yu, S.J., Terriere, L.C.: Ecdysin metabolism by soluble enzymes from three species of Diptera and its inhibition by the insect growth regulatar TH-6040. Pestic. Biochem. Physiol. 7, 48-55 (1977) 